\section{AL-AZHAR Dental Journal}

F $\quad \mathrm{O} \quad \mathrm{r}$
The Official Publication of The Faculty of Dental Medicine For Girls, Al-Azhar University Cairo, Egypt.

Print ISSN 2537-0308 • Online ISSN 2537-0316

ADJ-for Girls, Vol. 8, No. 4, October (2021) — PP. 591:600

\title{
Biological Pulp Response of Pulpine, Polyamidoamine Dendrimer and Their Combination in Dogs and their Remineralizing Effect on Carious Affected Human Dentin: A Randomized Clinical Trial
}

\author{
Mona R. Abo EL Wafa ${ }^{1 *}$, Maha A. Niazy ${ }^{2}$, Eman A. Abo Hagar ${ }^{3}$, Ashraf M. Abu-Seida ${ }^{4}$.
}

Codex : 08/21.10

azhardentj@azhar.edu.eg

http://adjg.journals.ekb.eg

DOI: $10.21608 /$ adjg.2021.50064.1321

Restorative Dentistry

(Removable Prosthodontics, Fixed

Prosthodontics, Endodontics, Dental Biomaterials, Operative Dentistry)

\section{KEYWORDS}

Polyamidoamine dendrimer,

Biomimetic remineralization, caries affected dentin.

\begin{abstract}
Purpose: This study was conducted to evaluate the biological pulp response to Pulpine and Polyamidoamine Dendrimer and their combination in dogs and comparing their remineralizing potentials on human caries affected dentin. Materials and Methods: Forty-five teeth in 3 mongrel dogs were randomly divided into 3 groups according to the applied pulp capping material; group A1: Pulpine NE, group A2: PAMAM G3 and group A3: Pulpine and PAMAM. Class V cavities were prepared; the pulps were mechanically exposed and finally restored with resin modified glass ionomer. Histological evaluation was performed after 2 weeks, 1 and 2 months. The in vivo study was designed as a randomized, unicenter, parallel, two arms, doubleblind split mouth clinical trial with 1:1 allocation ratio. The subjects who fulfilled the eligibility criteria were asked to participate and signed informed consent. Twenty-eight adhesive occlusal cavities were prepared; infected dentin was removed leaving carious affected dentin at the pulpal floor and divided into 2 groups; P1 (Pulpine) and P2 (Pulpine and PAMAM). Remineralization was assessed radiographically at base line, 1, 3 and 6 months. Results: In the animal study, there was no statistically significant difference among the tested direct pulp capping materials regarding the inflammation intensity, dentin bridge continuity or morphology. For the clinical trial, P2 group showed statistically significant higher dentin density at all study intervals. Conclusion: Pulpine and PAMAM enhanced pulp tissue repair. PAMAM could induce biomimetic remineralization of caries affected dentin.
\end{abstract}

- Paper extracted from Doctor Thesis Titled "Biological Pulp Response of Pulpine, Polyamidoamine Dendrimer and their Combination in dogs and their Remineralizing Effect on Carious Affected human dentin".

1. Assistant lecturer of operative dentistry, Faculty of Dentistry, Misr University for Science and Technology, Cairo, Egypt.

2. Professor of operative dentistry, Faculty of Dental Medicine for Girls, Al-Azhar University, Cairo, Egypt.

3. Professor of oral pathology, Faculty of Dental Medicine for Girls, Al-Azhar University, Cairo, Egypt.

4. Professor of surgery, anesthesiology and Radiology. Faculty of Veterinary Medicine. Cairo University, Cairo, Egypt.

* Corresponding author email: dr.monarizk@yahoo.com 


\section{INTRODUCTION}

As the pulp offers nutrients and serves as a biosensor for identification of the pathogenic stimuli, pulp vitality is extremely essential for tooth viability. Vital Pulp therapy aims to preserve the vitality of the dental pulp, and to stimulate the remaining pulp to regenerate the dental pulp complex. In direct pulp capping technique, a protective agent is applied directly over the injured pulp to protect the pulp tissue from further damage, and to promote the regeneration of dentin-pulp complex ${ }^{(1)}$.

Among the common oral diseases are dentin caries and hypersensitivity; both are associated with demineralized dentin that is mainly composed of collagen fibrils, which are not capable to start hydroxyapatite (HA) nucleation and growth. Noncollagenous proteins (NCPs) which present in the organic matrix of dentin, play a very important role in dentin biomineralization. In between the gap zones of collagen fibrils, a series of NCPs have the ability for being nucleation templates that regulate HA growth during biomineralization. For the remineralization of demineralized dentin, good nucleation templates that can securely attach to collagen fibrils are needed ${ }^{(2)}$.

As the result, the main concern is to develop biocompatible materials that can induce normal dentin-pulp complex like Hoffmann's Pulpine NE, a recent Eugenol- free biocompatible MTA alternative for direct and indirect pulp capping which contains propolis, a natural product that has shown to possess potent antimicrobial and antiinflammatory properties. It has been reported that Poly amidoamine (PAMAM) dendrimer, which is sometimes referred to as "artificial protein" have been widely used in the biomineralization field (3). In addition due to its mono-dispersed molecular weight within the size retention range of collagen, PAMAM-NH2 can be sustained on the dentin surface. PAMAM-NH2 may be considered as an excellent template for inducing remineralization ${ }^{(4)}$.

Accordingly, the null hypotheses tested are as follows: i) there is no difference in the response of dogs' pulp tissue to Pulpine NE, PAMAM G3 and their combination. ii) there is no difference in the remineralization potential of Pulpine NE alone and in combination with PAMAM G3 on human caries affected dentin.

\section{MATERIALS AND METHODS}

\section{1- Animal Study:}

\section{Selection and care of the experimental animals:}

All the experimental procedures in the research were carried out in the department of Veterinary Surgery, Faculty of Veterinary Medicine, Cairo University and in accordance with Research Ethics Committee, Faculty of dental medicine for Girls, Al-Azhar University (REC17-01123). Three healthy mongrel dogs with intact dentition were enrolled in the current experimental study. The dogs were housed in separate kennels that were sprayed with Neocidal (1/1000) and then were injected subcutaneously with Ivermectin at a rate of $0.2 \mathrm{mg} / \mathrm{kg}$ to control external and internal parasitic infections ${ }^{(5)}$.

\section{Experimental study grouping:}

One experimental dog was included in each phase. Five teeth in three quadrants of the dog jaws $(n=45)$ were randomly selected for either of the pulp capping material; (A1) Pulpine NE, (A2) PAMAM dendrimer while (A3) pulp capped with combination of both materials. Each experimental group was subdivided into three subgroups according to the assessment time (T), where $\mathrm{T} 1$ represents assessment of the pulp after two weeks, (T2) after one month and (T3) after two months respectively.

\section{Preoperative animal preparation and premedication:}

The dogs were not fed for twelve hours prior to the operation. The dogs were subcutaneously injected with atropine sulphate at a dose rate of $0.05 \mathrm{mg} / \mathrm{kg}$ body weight 15 minutes prior to induction of anesthesia to reduce salivation ${ }^{(6)}$. 


\section{Pulp capping procedures:}

The anesthesia was induced by injection of a mixture of xylazine $1.0 \mathrm{mg} / \mathrm{kg}$ body weight in combination with ketamine hydrochloride $5.0 \mathrm{mg} / \mathrm{kg}$ body weight into the cephalic vein for each dog and was maintained by injection of Thiopental sodium at a dose of $25 \mathrm{mg} / \mathrm{kg}$ by weight $2.5 \%{ }^{(6)}$. Class $\mathrm{V}$ cavities were prepared under cotton roll isolation on the buccal surface of the selected teeth $2 \mathrm{~mm}$ away from the gingival margin. Using round carbide bur under sterile cooling using saline solution, pulp exposure was performed in the middle of the pulp floor then light pressure using sterile cotton pellets was performed to control bleeding (7). Pulpine $\mathrm{NE}$ was mixed according to the manufacturer's instructions and applied directly over the exposed pulp by using a sterile condenser in group (A1), PAMAM G3 was applied using a disposable brush for group (A2) while for group (A3) a mixture of both materials was applied over the exposure area. Glass ionomer filling was used as final restorations. The dogs were given Carprofen $4.4 \mathrm{mg} / \mathrm{kg}$ tablet once daily for 15 days for pain relief until time of euthanasia.

\section{Animals' euthanasia and teeth preparation:}

After the assigned periods, the animals were euthanized by injecting $20 \mathrm{ml}$ of $5 \%$ thiopental sodium solution rapidly through the cephalic vein. The maxilla and the mandible were surgically removed and separated at the midline into two halves ${ }^{(5)}$. The jaws with the teeth were directly fixed in formaldehyde solution $10 \%$.

\section{Preparation for histological study:}

The teeth were fixed for two weeks in $10 \%$ buffered formalin solution. The specimens were demineralized in Morse's solution for four months. After complete decalcification, the specimens were dehydrated with ethanol at varying concentrations. The teeth were eventually embedded in paraffin wax and serially sectioned in a buccolingual direction using a microtome ${ }^{(8)}$. All sections were stained with Hematoxylin- eosin stain. All the images of the slides were captured and analyzed using computed image analysis system (Leica Qwin, 500 Software, Germany), at Oral and Dental Pathology Department, Faculty of Dental Medicine for Girls, Al -Azhar University. The images were analyzed and scored according to certain criteria ${ }^{(9)}$.

\section{Statistical analysis:}

It was performed using a commercially available software program (SPSS 18; SPSS, Chicago, IL, USA). Chi square test was used between groups and within intervals. The level of significance was set at $\mathrm{P} \leq 0.05$.

\section{In vivo study:}

\section{Trial registration and Ethical Approval:}

The trial was registered online in clinical trial. gov Protocol Registration and Results System (PRS) with identification number (ID: NCT04262076). The research protocol was also approved by Ethics Research Committee, Al- Azhar University. The Ethical Approval certificate registration number was (REC17-01123).

\section{Trial design and sample size calculation:}

A Randomized, Unicenter, Parallel, Two arms, Double -blind split mouth clinical trial with 1:1 allocation ratio was executed at the dental clinic of conservative dentistry at Faculty of Dental Medicine for Girls, Al- Azhar University in Cairo; from July 2018 to January 2020. Recruitment of participants was done between July 2018 and August 2019. Sample size was calculated using $G^{*}$ power program, Germany and a total sample size of 12 patients (14 patients (28 cavities)) after increasing the sample size by about $17 \%$ to compensate for drop out) will be sufficient to detect an effect size of 1.22 , a power of 0.8 based on a previous study ${ }^{(10)}$. The CONSORT 2010 guidelines (Consolidated Standards of Reporting Trial) were followed to guarantee clear and transparent reporting in this research ${ }^{(11)}$. 


\section{3- Participant's Enrollment and Randomization:}

The samples selected to be enrolled in this clinical trial were from patients of both sexes who regularly visit conservative dentistry clinic at Faculty of Dental Medicine for Girls, Al-Azhar University. All patients who required posterior restorations and fulfilled inclusion criteria were asked to participate in this trial. Inclusion criteria ${ }^{(12)}$ mainly involved; both sexes aged between 18-25 years, with moderate and high risk index, with at least one tooth has occlusal caries that extend into dentin in both right and left side with no previous operative procedures and absence of spontaneous pain. Occlusal caries was examined clinically both visually by detecting color changes in the occlusal surface , by tactile sensation using a ball-tipped explorer and radiographically by taking periapical radiograph using parallel technique for assessment of caries depth. While exclusion criteria $(12,13)$ involved; patient with very poor oral hygiene, with compromised medical history and pregnant females. Also teeth with internal or external resorption or exhibiting any symptoms of pulp pathology had been excluded. All participants signed on their written informed consents before initiating the study. All consent forms were written in Arabic language to be easily understood by the volunteers. All procedures, purpose, risks, benefits and expected duration of the trial were explained to participants in a simple language. Participants (individuals) in this clinical trial were randomly assigned using a computer generated randomization by using a Microsoft ${ }^{\circledR}$ Excel Program. The participants and outcome assessor were blinded to allocation.

\section{Clinical procedures}

\section{A) Patient Preparation:}

Preoperative data for each patient was recorded in predesigned patient's chart. Each patient first received full mouth scaling and polishing procedure to clean the teeth surfaces and given proper oral hygiene instructions.

\section{B) Cavity preparation:}

First, a pre-operative digital radiograph was taken for the tooth to be treated using a digital imaging plate wrapped in a barrier envelope with a plastic parallel kit. After appropriate local anesthesia (Mepecaine-L) $1 \mathrm{mg}$ had been administered, rubber dam isolation was performed using heavy consistency latex rubber dam sheet. Following the principles of minimally invasive dentistry cavity preparation that was carried out using \#330 and \#245 carbide burs with copious amounts of water coolant then by using sharp spoon excavator remaining soft caries was removed. Caries indicating dye was utilized to identify the type of carious dentin at the pulpal floor either infected or affected. The stained outer caries affected dentin was totally removed till the firm unstained caries affected dentin that was assessed using sharp explorer.

\section{C) Intervention:}

The tested remineralizing materials were prepared and placed over the firm caries affected dentin at the cavity floor according to the manufacturer's instructions. In group (P1) Pulpine NE was used, while in group (P2) Pulpine and PAMAM G3 (combination of both materials) were used, where one drop of PAMAM dendrimer was applied on the floor of the cavities by using a disposable brush with rubbing motion to allow proper infiltration of the material into the dentin and left for 30 seconds then rinsed by using a plastic syringe filled with deionized water ${ }^{(2)}$. The cavities were then gently dried with cotton pellet then a homogenous mix of Pulpine was prepared by mixing the powder and liquid according to the manufacturer's instructions and applied over the pulpal dentin surface by sterile condenser followed by removal of the excess of the material.

\section{D) Restorative procedures and outcome assessment:}

A bulk fill posterior resin composite restorative material (X-tra fil) was used after enamel surfaces were etched for 15 seconds and rinsed for $20 \mathrm{sec}-$ 
onds, excess water was gently removed with air/ water syringe to avoid dehydration of dentin. A universal bonding agent (Futurabond $\mathrm{M}^{+}$) was applied with a disposable brush and light activated for 20 seconds. Composite was inserted into the prepared cavity as one increment, packed, carved to resemble normal occlusal anatomy then light-cured for 40 seconds. With fine-grit diamond burs, polishing discs and rubber tips finishing and polishing of all restorations were carried out under water cooling. All the restorations were imaged at (base line, 1month, 3 months and 6 months) utilizing DBSWin software a part of Durr Vista Scan (digital scanner) that was used for assessment of remineralization of dentin. The restorations were evaluated for the outcome by single experienced, calibrated independent assessor. The mineral density mean value was calculated from the equation (average density $=a v-$ erage intensity/profile); the profile was determined directly in the utilized software ${ }^{(14)}$.

\section{Statistical analysis}

Statistical analysis was carried out using a commercially available software program (SPSS 18; SPSS, Chicago, IL, USA). Data were explored for normality using Kolmogorov-Smirnov test. For parametric data, independent $t$ test was used to compare both groups, while One way analysis of variance (ANOVA) test served for comparison of different observation times within the same group, this was followed by Tukey's post hoc testy when ANOVA test revealed a significant difference.

\section{RESULTS}

\section{Animal Study:}

\section{Histological findings:}

At 2 weeks observational period, histopathological examination of specimens of both $\mathrm{A} 1$ and $\mathrm{A} 2$ groups showed intense acute inflammatory reaction in majority of the specimens just beneath the exposure site. The cells of the odontoblastic layer appeared intact outlining the pulp space with their normal arrangement. Some dilated blood vessels and small variable edematous spaces were noticed in coronal and middle portions of the pulp tissue. No dentin bridge or calcified material was observed in the pulp tissue. While for A3 group incomplete dentin bridge was observed in $40 \%$ of the specimens similarly pulp tissue inflammation was also observed beneath exposure site.

At 1 month, in group A1 complete dentin bridge was observed in $20 \%$ of the specimens. Disturbance of the normal architecture of the pulp was noticed with area of tissue degeneration just beneath dentin bridge accompanied by fatty degeneration or vacuolization of the lining odontoblastic cells. Areas of tubular calcification, vasodentin and osteodentin were also observed. While in group A2 incomplete dentin bridge was mainly observed. Pulp tissue beneath the exposure area showed areas of degeneration and loss of normal orientation. Moreover, there was complete loss of the lining odontoblastic layer cells at the same side of the exposure. Inflammatory cells were still found in the pulp core close to the dilated blood vessels. In group A3 specimens showed similar formation and distribution of dentin bridge as in group A1 with large areas of pulp tissue degeneration beneath the dentin bridge while the remaining pulp tissue showed hyaline degeneration accompanied by degenerative changes in the odontoblasts that exhibited fatty degeneration. (fig.1). At 2 months, complete dentin bridge was noticed in $80 \%$ of the specimens in A2 and A3 groups while $20 \%$ in these groups revealed partial dentin bridge. Whereas in group A1 only 40\% showed complete dentin bridge and $20 \%$ showed partial dentin bridge $80 \%$ of specimens in all groups showed few inflammatory cells (fig. 1 ).

\section{Statistical analysis:}

Chi square test revealed that the difference between the tested groups was not statistically significant regarding the inflammation intensity, dentin bridge continuity and morphology. Table (1). 

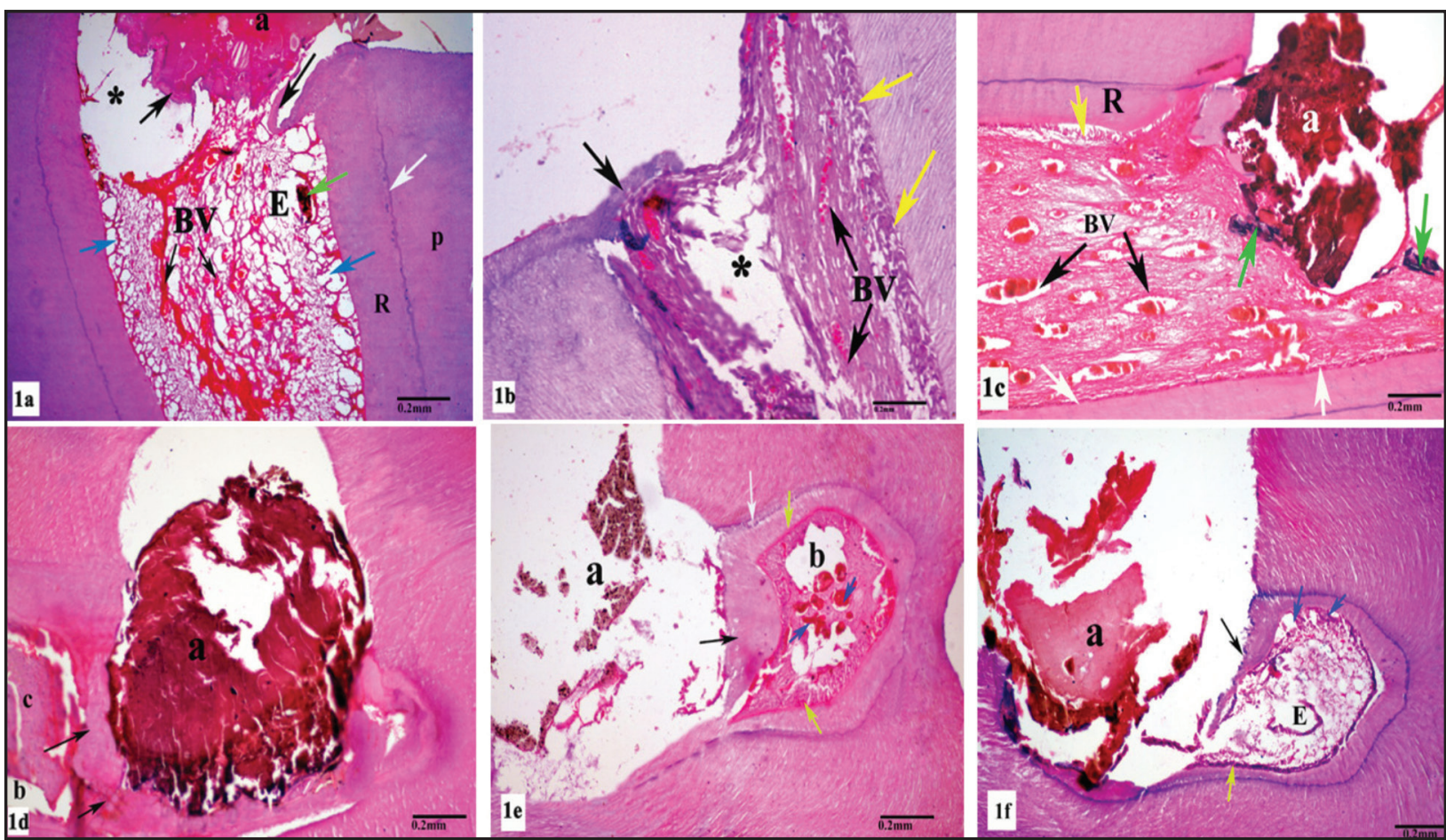

Figure (1) A photomicrograph of pulp capped with Pulpine (A1),PAMAM (A2) and Pulpine/PAMAM (A3) showing:(1a) group (A1) at 1month, complete dentin bridge (black arrows), dilated blood vessels (BV), pulp tissue degeneration $(*) ;(\mathbf{1 b})$ group (A2) at 1 month, partial dentin bridge (black arrow), intact odontoblasts (yellow arrows);(1c) group (A3) at 1month, partial dentin bridge in contact with the capping material (a) dilated blood vessels (BV);(1d) Group (A1) at 2months,complete dentin bridge (black arrow); (1e) Group (A2) at 2 months dilated blood vessels (blue arrows);(1f) Group (A3) at 2 months complete dentin bridge (black arrow),edematous area (E) and fatty degeneration of odontoblasts (blue arrow).

Table (1): Comparison of histological scores [No. (\%)] of dentine bridge continuity in different groups within the same observation time (Chi square test).

\begin{tabular}{|c|c|c|c|c|c|c|c|c|c|}
\hline \multirow{4}{*}{ Variables } & \multicolumn{9}{|c|}{ Dentine bridge continuity } \\
\hline & \multicolumn{3}{|c|}{ T1 (2 weeks) } & \multicolumn{3}{|c|}{ T2 (1 month) } & \multicolumn{3}{|c|}{ T3 (2 months) } \\
\hline & A1 & A2 & A3 & A1 & A2 & A3 & A1 & A2 & A3 \\
\hline & n $(\%)$ & n $(\%)$ & n (\%) & n $(\%)$ & n $(\%)$ & n $(\%)$ & n $(\%)$ & n $(\%)$ & n $(\%)$ \\
\hline Score 1 & 0 & 0 & 0 & $1(20)$ & 0 & $1(20)$ & $2(40)$ & $4(80)$ & $4(80)$ \\
\hline Score 2 & 0 & 0 & $2(40)$ & $1(20)$ & $4(80)$ & $4(80)$ & $1(20)$ & $1(20)$ & $1(20)$ \\
\hline Score 3 & 0 & 0 & 0 & $1(20)$ & $1(20)$ & 0 & $2(40)$ & 0 & 0 \\
\hline Score 4 & $5(100)$ & $5(100)$ & $3(60)$ & $2(40)$ & 0 & 0 & 0 & 0 & 0 \\
\hline $\mathbf{X}^{2}$ & \multicolumn{3}{|c|}{4.62} & \multicolumn{3}{|c|}{8} & \multicolumn{3}{|c|}{4.8} \\
\hline $\mathbf{P}$ & \multicolumn{3}{|c|}{$0.59 \mathrm{~ns}$} & \multicolumn{3}{|c|}{$0.238 \mathrm{~ns}$} & \multicolumn{3}{|c|}{$0.569 \mathrm{~ns}$} \\
\hline
\end{tabular}

Significance level $P \leq 0.05$, *significant. 


\section{In vivo study:}

The results revealed that caries affected dentin capped with Pulpine NE and PAMAM dendrimer (group P2) recorded higher mean value in mineral density compared to Pulpine NE (group P1) with a statistically significant difference between both groups at the different assessment intervals. Table (2).

Table (2): Mean and standard deviation of dentin mineral density (radio-density) and comparison between both groups (independent t test):

\begin{tabular}{|c|c|c|c|c|c|c|c|c|}
\hline \multirow{2}{*}{$\begin{array}{c}\text { Assessment interval } \\
\text { Remineralizing } \\
\text { materials }\end{array}$} & \multicolumn{2}{|c|}{$\begin{array}{c}\text { T1 } \\
\text { (Base line) }\end{array}$} & \multicolumn{2}{|c|}{$\begin{array}{c}\text { T2 } \\
\text { (1month) }\end{array}$} & \multicolumn{2}{|c|}{$\begin{array}{c}\text { T3 } \\
\text { (3months) }\end{array}$} & \multicolumn{2}{|c|}{$\begin{array}{c}\text { T4 } \\
\text { (6 months) }\end{array}$} \\
\hline & P1 & P2 & P1 & P2 & P1 & P2 & P1 & P2 \\
\hline Mean & 0.083 & 0.094 & 0.110 & 0.129 & 0.126 & 0.155 & 0.143 & 0.173 \\
\hline SD & 0.004 & 0.004 & 0.003 & 0.004 & 0.002 & 0.005 & 0.003 & 0.005 \\
\hline t & \multicolumn{2}{|c|}{6.149} & \multicolumn{2}{|c|}{12.02} & \multicolumn{2}{|c|}{17.03} & \multicolumn{2}{|c|}{16.27} \\
\hline $\mathbf{P}$ & \multicolumn{2}{|c|}{$0.000 *$} & \multicolumn{2}{|c|}{$0.000 *$} & \multicolumn{2}{|c|}{$0.000 *$} & \multicolumn{2}{|c|}{$0.000^{*}$} \\
\hline
\end{tabular}

Significance level $P \leq 0.05$, *ignificant.

\section{DISCUSSION}

Maintenance of pulp vitality is a concerning issue in contemporary restorative dentistry. Dental pulp is a distinctive soft tissue, consists of blood vessels, nerve fibers, collagen fibers, fibroblasts, odontoblasts, and immune cells, and has the potential for healing like other connective tissues. Direct pulp capping (DPC) is one of the strategies of vital pulp therapy, seeking to preserve the integrity of pulpal tissue ${ }^{(1)}$.

The choice of the material for pulp capping significantly determines the effectiveness of vital pulp therapy. As well as possessing adequate biocompatibility and strong antibacterial activity, an ideal pulp capping agent must be able to induce the formation of reparative dentin ${ }^{(5)}$.

Inducing the remineralization of hypomineralized carious dentin thereby protecting and preserving the vital pulp is the major challenge for the modern approach in restorative dentistry ${ }^{(15)}$. Regeneration of caries-affected dentin is a desirable therapeutic approach that contradicts the con- ventional procedure in which the tissue is entirely eliminated from the dental preparation ${ }^{(16)}$. Pulpine NE (Eugenol- free biocompatible MTA alternative) that is used for direct and indirect pulp capping, was selected for the present study aiming for dentin bridge formation with preservation of pulp vitality and inhibition of pulp necrosis. PAMAM NH $\mathrm{N}_{2}(\mathrm{G} 3)$ dendrimer was selected in this study which is expected to duplicate the effects of NCPs and induce dentin remineralization.

The experimental animal study was selected as the animal model is easy to work, enabling long term evaluation with the potential of providing comparative evaluation of the various materials tested. In current research protocol dogs were the chosen animal model because the mechanism of dentin induction and synthesis in these animals are similar to that in human being ${ }^{(5,17)}$. The pulp response assessment was carried out over three separate periods, one short period of two weeks to track the initial inflammatory reaction to the three tested materials. Two longer observation periods of 1 month and 2 months were selected to evaluate the progressive 
changes in the pulp tissue regarding inflammatory reaction and reparative dentin formation ${ }^{(18)}$. Histological analysis is considered the real "gold standard" of pulp status because clinical signs, symptoms and radiologic appearance cannot ascertain the true state of the pulp health or pathology ${ }^{(19)}$.

As randomized clinical trials (RCT) are widely recognized to be the best design and gold standard for the evaluation of experimental treatments, a randomized clinical trial was used for the in-vivo part of the research. Additionally, the internal validity of comparison between new therapies was verified by the random assignment of patients to different treatment groups ${ }^{(20)}$.

In the current study, single visit caries excavation leaving only caries affected dentin at the cavity floor was performed as this approach has a lower risk for pulp exposure than two- visit selective caries excavation and enables the affected dentin at the cavity floor to be mineralized ${ }^{(10,21)}$. Caries detector dye was used as it has been shown to be useful in the detection and removal of caries affected den$\operatorname{tin}^{(22)}$. Digital radiographic density measurement integrating X-ray radiography with digital image processing (Vista Scan-system) was used to monitor the remineralization process to identify the amount of minerals attained in the tooth structure using different treatment modalities. This technique offers lower radiation exposure, non invasive and precise image analysis ${ }^{(23) .}$

Regarding inflammation intensity of the pulp tissue at 2 weeks the histopathological results revealed intense inflammatory reaction in specimens of all groups. The early stage of the healing process is the inflammatory reaction. The fibroblasts would soon migrate toward the wound, proliferate and produce large quantities of collagen matrix at the time the tissue is injured, helping to separate and heal the damaged tissue ${ }^{(24)}$. At 1 month observational period, there was a slight reduction in the intensity of inflammatory pulp reaction in all groups with insignificant difference between the three groups. The reduction in severity of the inflammation in group (A1) and (A3) could be attributed to anti- inflammatory properties of propolis that is the main component of Pulpine NE. It was known that flavonoids and caffeic acid found in propolis have a major role in decreasing the inflammatory response by blocking the arachidonic acid's lipoxygenase pathway moreover, by stimulating phagocytic activities and inducing cellular immunity, flavonoids and caffeic acid trigger the immune system ${ }^{(25)}$. Similarly, after 2 months the results showed that the intensity of the inflammatory pulp reaction have been greatly reduced in all groups which may be attributed to the accelerated tissue repair and excellent biocompatibility of the materials and it was found that the difference was not statistically significant between the tested materials.

Regarding dentin bridge continuity and morphology, at two weeks; there was no dentin bridge formation in group (A1) and group (A2) in all the specimens while only 2 specimens in group (A3) showed partial dentin bridge this might be attributed to the need of longer period of direct contact of the tested materials to the pulp tissue ${ }^{(26)}$. At 1 month, the majority of the specimens of groups (A2, A3) showed partial dentin bridge while in group (A1) only $20 \%$ showed partial dentin bridge. However, $20 \%$ of specimens in groups (A1, A3) revealed complete dentin bridge that was in the form of irregular hard tissue deposition accompanied with some areas of pulp calcification but the difference between groups was not statistically significant. While after 2 months; the scores of the dentin bridge continuity and morphology was decreased with time which means improvement in quality of the formed dentin bridges in the 3 groups. Moreover, these scores exhibited a statistically significant difference when compared to those recorded at 2 weeks and 1 month for each of the tested materials.

In group (A1) partial and complete dentin bridge formation was found after 1 and 2 months that could be attributed to the presence of two important ingredients in Pulpine NE, calcium hydroxide, that is present in a very low concentration, that is well known for its ability for reparative dentin formation and its antibacterial properties beside 
its low concentration that aid in elimination of the possible side effect as pulp tissue necrosis. The second is propolis, which inhibits apoptosis by inhibiting the translation of NFk $\beta$ (Nuclear factor NF-Kappa B) into the nucleus. Apoptosis inhibition leads to the prevention of a dramatically decrease in the amount of fibroblast in the pulp. Propolis extract enhances the differentiation of odontoblast like cells, stimulates the chemotaxis of fibroblasts to increase the production of collagen, fibronectin, and proteoglycans ${ }^{(24)}$. These results are in accordance with a study which found that dentin bridge was formed following pulp capping with propolis in most of the samples after 2 months ${ }^{(26)}$.

Similarly in group (A2), at1 month and 2 months observational periods partial and complete dentin bridge formation occurred respectively. This may be due to effect of PAMAM dendrimer in stimulating the odontogenic potential and differentiation of dental pulp cells which help in hard tissue formation and mineralization. This is in line with a study which found that dental pulp cells displayed a strong binding and uptake with PAMAM dendrimers (G5) and demonstrated increased gene expression of dentin matrix protein (DMP-1), dentin sialoprotein (DSPP), vascular endothelial growth factor (VEGF) and matrix extracellular phosphoglycoprotein $(\mathrm{MEPE})^{(4)}$. Dentin bridge was also observed after 1 month and 2 months in group (A3) may be related to the possible positive combined effect of the both tested materials on the healing of dental pulp and stimulation of dentin bridge formation.

The results of the clinical trial revealed that treatment of caries affected dentin with PAMAM G3 prior to placement of Pulpine NE group (P2) showed significantly higher mean mineral dentin density values at the different assessment intervals when compared to Pulpine alone (P1). The combination of Pulpine and PAMAM G3 may have a good remineralizing potential on caries affected dentin owing to their synergistic effect. These findings could be related to the application of PAMAM dendrimer on caries affected dentin before placement of Pulpine NE which could be considered an excellent nucleation template and can trigger the process of remineralization by absorbing $\mathrm{Ca}$ and $\mathrm{P}$ ions ${ }^{(27,28)}$ mimicking the function of noncollagenous proteins (NCPs) that play a vital role in the modulation of the biomineralization process.

\section{CONCLUSIONS}

Under limitation of this study the following could be concluded:-

1. Pulpine NE, PAMAM dendrimer G3 and their combination have the ability to stimulate dentin bridge formation when used for direct pulp capping and similarly could enhance pulp tissue repair thus the first null hypothesis was accepted.

2. PAMAM dendrimer $\mathrm{G} 3$ could inducebiomimetic remineralization of caries affected dentin when used in combination with Pulpine NE thus the second null hypothesis was rejected.

\section{ACKNOWLEDGEMENT}

The authors are grateful and wish to thank Dr. Hagar Abd El Nabi , Assistant professor of Endodontic department, Faculty of Dental Medicine, Al-Azhar University for her valuable help and support in the animal study.

\section{REFERENCES}

1. Bidar M, Moushekhian S, Gharechahi M, Talati A, Ahrari F, Bojarpour M. The effect of low-level laser therapy on direct pulp capping in dogs. J Lasers Med Sci. 2016; 7:177- 83.

2. Khater AA, Niazy MA, Gad NA. The effect of polyamidoamine dendrimer, gluteraldehyde and their combination on microhardness and micromorphology of demineralized dentin. ADJ.2018; 5:341-7.

3. Liang K, Xiao S, Weir MD, Bao C, Liu H, Cheng L, et al. Poly (amido amine) dendrimer and dental adhesive with calcium phosphate nanoparticles remineralized dentin in lactic acid. J Biomed Mater Res. 2017; 106:2414-24.

4. Bapat RA, Dharmadhikaris S, Chaubal TV, Amin MC, Bapat P, Gorain B, et al. The potential of dendrimer in delivery of therapeutics for dentistry. Heliyan. 2019; 5:e02544-55. 
5. Negm AM, Hassanien EE, Abu-Seida AM, Nagy MM. Biological evaluation of a new pulp capping material developed from Portland cement. Exp Toxicol Pathol. 2017; 69:115-22.

6. El-Tayeb MM, Abu-Seida AM, El Ashry SH, El-Hady SA. Evaluation of antibacterial activity of propolis on regenerative potential of necrotic immature permanent teeth inDogs. BMC Oral Health. 2019; 19:174-85.

7. Akhavan A, Arbabzadeh F, Bouzari M, Razavi S M, Davoudi A. Pulp response following direct pulp capping with dentin adhesives and Mineral Trioxide Aggregate; An animal study. Iran Endod J 2017; 12: 226-30.

8. Abdelaz P, El Zoghbi A, Shokry M, Ahmed A, Rasha H. Reparative dentin formation using stem cell therapy versus calcium hydroxide in direct pulp capping: An animal study. Braz Dent J. 2019; 30: 542-9.

9. Nowicka A, Aagocka R, Lipski M, Parafiniuk M, Grocholewicz K, et al. Clinical and histological evaluation of direct pulp capping on human pulp tissue using a dentin adhesive system. BioMed Res Int. 2016; 4:1-9.

10. Harahap NU, Djauharie N, Asrianti D. Affected dentin remineralization after partial caries excavation (in vivo): the effect of iRoot ${ }^{\circledR}$ BP Plus application. IOP Conf. Series: J Physics: Conf. Series. 2018; 1-8.

11. Pandis N, Chung B, Schere R, Elbourme D, Altman D. Research method and reporting: CONSORT 2010 Statement extension check list for reporting within person randomized trial. BMJ. 2017; 357:1-22.

12. Ibrahim SA, Niazy MA, El-Yasaky MA, El-Kilani NS. Effect of Nanohydroxyapatite with and without chlorhexidine on remineralization of carious dentin at different intervals: An in vivo study. ADJ.2016; 3:171-6.

13. Al-Sabri FA, El-Marakby AM, Abdulrab S, Al-Shamiri HM, Al-Mansoub T. Effect of calcium hydroxide on deep caries dentin: A clinical study. J Clin Res Dent. 2019; 2:1-4.

14. Elasser DM, Niazy MA, El Sharkawy DA, Mansour MSh. The remineralization potential of NanoBioactive glass versus nanohydroxyapatite on dentine as affected by $\mathrm{PH}$ cycling. ADJ. 2018; 5:327-34.

15. Kunert M, Szymanska M. Bio-Inductive materials in direct and indirect pulp capping - A review article. Materials. 2020; 13: 1204-24.

16. Ferreira G, Inés M. Bioactive materials in dentin remineralization. Odontoestomatologia. 2016; 18:11-8.
17. Muthanandam S, Muthu J, Mony V, Parvathy RL, Prem LK. Animal models in dental research- A review. IDJSR.2020; 8:44-7.

18. Yun JY, Choi YH, Kim YK, Um IW, Park JC, Kim JY. Experimental study of pulp capping using xenogenic demineralized dentin paste. J Hard Tissue Biol. 2016; 25: 321- 8 .

19. Al Saudi KW, Nabih SM, Farghaly AM, Abo hagar EA. Pulp repair after direct pulp capping with new bioceramic material A comparative histological study. Saudi Dent J. $2019 ; 31 ; 469-75$

20. Baghbaninaghadehi F, Armijo-olivo S, Woodhouse L. Fundamentals of randomization in clinical trial. IJANHS 2016; 4:174-87.

21. Essam M, Niazy MA, Farouk H, Mostafa AA. The remineralizing effect of incorporating $\mathrm{Ca}$ - phosphate and Ca-fluoride nanoparticles into self- etch adhesives used in restoring class I cavities. ADJ. 2019; 6:231-8.

22. Pratiwi AR, Meidyawati R, Djauharie N. The effect of MTA application on the affected dentine remineralization after partial caries excavation (in vivo). J Phys Conf Ser. 2017; 884:1-6.

23. Harhash A, Salem G. Radiographic evaluation of non operative repair depths for various preventive approaches. RJPBCs. 2017; 8:290-9.

24. Dwiandhono I, Effendy R, Kunarti S. The thickness of odontoblast-like cell layer after induced by propolis extract and calcium hydroxide. Dent J. 2016; 49: 17-21.

25. Khurshid Z, Naseem M, Zafar MS, Najeeb S, Zohaib S Propolis: A natural biomaterial for dental and oral health care. J Dent Res Dent Clin Dent Prospect. 2017; 11:265-74.

26. Saleh RS, Nagi SM, Khallaf ME, Abd El-Alim SH, Zaazou MH, Abu-Seida AM, et al. In-Vivo assessment of dentin bridge formation after using MTA and experimental propolis paste as direct pulp capping material. RJPBCS 2016; 7: 1244- 50 .

27. Liang K, Wang S, Tao S, Xiao S, Zhou H, Wang P, et al. Dental remineralization via poly (amido amine) and restorative materials containing calcium phosphate nanoparticles. Int J Oral Sci 2019; 11:15-27.

28. Bae J, Son WS, Yoo KH, Yoon SY, Bae MK, Lee DJ, et al. Effects of Poly (Amidoamine) Dendrimer-Coated Mesoporous Bioactive Glass Nanoparticles on Dentin Remineralization. Nanomaterials. 2019; 9:591-606. 